\title{
Self-reported hypertension and job strain in nursing personnel: Assessing two different formulations of the demand-control model
}

\author{
Luciana Fernandes Portela *1, Rosane Härter Griep², Paul Landsbergis ${ }^{3}$, Lúcia Rotenberg ${ }^{2}$ \\ ${ }^{1}$ National School of Public Health, Oswaldo Cruz Foundation, Brazil \\ ${ }^{2}$ Laboratory of Health and Environment Education, Oswaldo Cruz Institute, Oswaldo Cruz Foundation, Brazil \\ ${ }^{3}$ School of Public Health, Downstate Medical Center, State University of New York, USA
}

Received: July 7, 2014

DOI: $10.5430 /$ cns.v3n2p46
Accepted: November 27, 2014 Online Published: January 8, 2015

URL: http://dx.doi.org/10.5430/cns.v3n2p46

\begin{abstract}
Object: This study analyzed the association between job strain and self-reported hypertension.

Methods: A cross sectional study concerning nursing professionals involved with patient care was performed at three hospitals in Rio de Janeiro, Brazil, in 2005-2006. The sample comprised 1,307 female workers (participation rate: 81.9\%). Job strain was assessed according to two different formulations of the demand-control model: the traditional quadrant term and the quotient term. Adjusted prevalence ratio was calculated using generalized liner models with binomial distribution and Poisson link (robust estimator).
\end{abstract}

Results: The association between self-reported hypertension and job strain was statistically significant only when job strain was evaluated using the ratio between demand and control. Workers in the highest quartile of job strain (quotient term) were 1.54 times more likely to report hypertension than the reference group.

Conclusions: These results are particularly interesting considering that self-reported hypertension can be used as an alternative to situations where using blood pressure monitors is not feasible, particularly in studies with big samples.

Key Words: Hypertension, Psychosocial stress, Occupational health, Nursing

\section{Introduction}

The contemporary work environment is the locus in which adults spend a great part of their living hours conducting activities that can be demanding, constraining and stressful. ${ }^{[1]}$ In this context, special attention has been given to cardiovascular risk factors (hypertension, obesity, smoking habits, metabolic syndrome) and their relation with occupational stress. Waldron, et al. ${ }^{[2]}$ argued that arterial hyper- tension was a socially defined disease, typical of industrialized societies. The increase in the incidence of hypertension worldwide ${ }^{[3]}$ parallels transformations in the nature of work due to economic globalization, including increases in work stressors. $^{[1,4]}$

A number of studies have emphasized the participation of a stressful psychosocial environment at work on cardiovascular health. ${ }^{[5]}$ The job strain model, developed by

\footnotetext{
*Correspondence: Luciana Fernandes Portela; Email: luportela@yahoo.com; Address: Pav. Lauro Travassos, Avenida Brasil, 4365 - Manguinhos, Rio de Janeiro - CEP: 21040-900. RJ, Brazil.
} 
Robert Karasek, ${ }^{[6]}$ represented a breakthrough in psychosocial work environment research. According to this model, the combination of high psychological demands and low control over work can be a risk factor for cardiovascular diseases $^{[1]}$ and for the elevation of the arterial blood pressure. ${ }^{[7,8]}$

In the job strain model (or demand-control model), the characterization of job stress is traditionally based on "quadrants", which are defined by dichotomizing the sample (or population) according to demand and control medians or means. ${ }^{[6]}$ According to this procedure, the psychosocial working conditions is divided into four categories: high strain (high demand and low control), low strain (low demand and high control), active job (high demand and high control) and passive job (low demand and low control) "High strain jobs" can produce harmful effects to worker's health since those workers are exposed to low decision latitude over their tasks while dealing with high psychological demands. Also damaging is the situation that combines low demand and low control ("passive jobs"), that can lead to loss of skills and interest. The "active jobs" is characteristic of management positions that lead to stimulation and personal development. Although the demands are excessive, they are less harmful since the workers can plan their working hours according to their will, and develop strategies to deal with their difficulties. The most favorable situation, "low strain jobs", combines low demand and high control over the working process. ${ }^{[9]}$

Other formulations have been introduced, especially the ratio between demand and control to define stress at work. This "quotient" term generates a continuous form of the variable that can be dichotomized at an arbitrary cut-off point. ${ }^{[10]}$ In fact, some authors have applied this approach using different cut-points, including the median value, ${ }^{[11,12]}$ the third tercile ${ }^{[13]}$ or the forth quartile of the distribution. ${ }^{[14]}$ Despite the large number of publications on this subject, there is no agreement regarding the best procedure to evaluate job strain.

Some studies on this area have benefit from ambulatory blood pressure monitoring (ABPM). However the high cost of ABPM equipment does not allow its utilization in large samples, in which self-report data are frequently used. ${ }^{[15]}$ Thus, the use of self-reports of the target population in epidemiological studies is obviously advantageous as they can be obtained readily for large samples without great expense. ${ }^{[3]}$ It is also noteworthy that most studies in this field focused on men, while data on women were more sparse and less consistent, ${ }^{[1]}$ so that the original concept of job strain was proposed by some authors to be more applicable to men than to women. ${ }^{[16]}$

The present study focuses on psychosocial work stress in an exclusively female sample of nursing professionals including nurses and nursing assistants. The paper analyzes

Published by Sciedu Press self-reported hypertension as an alternative measure in studies with large samples, when blood pressure monitoring is not feasible. The present paper contributes to this debate by focusing on self-reported hypertension among female workers.

The study evaluates psychosocial strain among nursing workers based on two formulations of the demand-control model: (1) the quadrant term, based on four combinations of psychosocial demand and control scores, and (2) the quotient term, derived from the ratio between the demand and the control scores. The objective of this study is to analyze the association between job strain and self-reported hypertension, considering the relevance of the arterial blood pressure in the work environment context.

\section{Methods}

\subsection{Sample and procedures}

A cross sectional study concerning all nursing workers involved with patient care was performed at three hospitals in Rio de Janeiro, Brazil, in 2005-2006. The sample comprised 1,307 female nursing workers (participation rate: $81.9 \%$ ) including registered nurses and nurses assistants. In relation to the tasks carried-out by nursing teams, the nursing assistants perform activities involving participation in nursing help, hygiene care and patient comfort. According to Brazilian legislation the nursing assistants can only carry out their activities under the orientation and supervision of a registered nurse, who, in general, performs management activities, assists seriously ill patients including those in a situation requiring knowledge of the scientific basis as well as more complex procedures and those needing immediate decisions.

Data collection was based on a comprehensive instrument ${ }^{[17]}$ that included information on the participant's sociodemographic characteristics, physical and mental health symptoms, life styles, sleep complaints and data regarding job control and psychological demands. Job strain was assessed by the demand-control model scale translated and adapted to Portuguese, ${ }^{[18]}$ which was analyzed in relation to psychometric properties. ${ }^{[19]}$ Cronbach's alpha values for the same sample here studied were $\alpha=0.71$ and $\alpha=0.50$ for the psychological demands and control, respectively. Interviewers were responsible to record the information from participants as a means to increase the accuracy of the data. Interviewers underwent a training course that covered the aims of the study and particular emphasis was placed on the peculiarities of this work category (e.g. work schedule, number of jobs).

\subsection{Exposure and outcome variables}

Job strain was assessed according to two different formulations of the demand-control model. First, the traditional quadrant term, formed by dichotomizing control and de- 
mand scores at the medians of the sample was used. ${ }^{[8]}$ The low strain group (defined by scores below the median for psychological demands and above the median for control scores) was chosen as the reference group for statistical analyses. The reference group was compared against the high strain group (defined by scores above the median for psychological demands and below the median for control scores); passive job group (defined by scores below the median for both psychological demands and control scores) and active job group (defined by scores above the median for both psychological demand and control scores). Second, a quotient term was constructed, defining job strain as the ratio between demands and control scores, which were dichotomized in the highest quartile of the distribution. The reference group comprised the subjects on the bottom quartile. All analysis considering the demand-control variables included 1,251 subjects due to missing information for this particular variable.

Self-reported hypertension was assessed by asking participants "Has a doctor or another professional in the health service ever told you that your blood pressure is or was high?" Possible answers were "Yes, just once", "Yes, more than once and on different days", "Yes, only while pregnant", and "No". The hypertensive group comprises those who answered "Yes", after excluding workers who reported hypertension only during pregnancy. Reliability of this measure in the test-retest Kappa was 0.78 ; $(95 \%$ confidence interval $[95 \% \mathrm{CI}]=0.74-0.82)$.

\subsection{Covariates}

Important covariates associated with health and with work were considered in the present study and tested as possible confounders. Socio-demographic variables included age, marital status (living/not living with a partner), family earnings ( $\geq 423.3 /<423.3$ USD) and self-reported skin color (white/mixed/black). Leisure-time physical activity was measured by the number of hours per week (more than 6 hours/1-6 hours/less than $1 \mathrm{hr}$ ). Body mass index was defined by self-reported weight $(\mathrm{kg}) / \mathrm{height}\left(\mathrm{m}^{2}\right)$. Smokers were defined as subjects who currently smoke or have smoked in the past. Alcohol use was measured by the consumption of alcohol drinks taken two weeks before the interview. Work-related variables included the number of jobs (one/ two or more), professional category (nurses/ nurses assistants), work schedule (day worker/ former night worker/ current night worker) and type of employment contract (permanent or temporary).

\subsection{Statistical analysis}

The relationship between job strain and self-reported hypertension was analyzed in two steps. The first one concerns the definition of confounders, which was based (1) on theoretical models described in literature and (2) bivariate chi-square tests; those with at least a minimum association $(p<.10)$ were selected for inclusion in the logistic 48 regression models. According to this criteria, age, income, self-reported skin color, education, marital status, BMI and smoking habits were included in the multivariate model.

The second refers to the prevalence ratio (PR) analysis, used to test the association between exposure variables and selfreported hypertension. ${ }^{[9]}$ Analysis including only age as a confounder, and associations adjusted for age and for each group of confounders are presented. Adjusted PR was calculated using generalized linear models with binomial distribution and Poisson link (robust estimator). Statistical procedures are based on a significance level of $p<.05$. Analyses were performed with SPSS (version 18.0) software.

\subsection{Ethical considerations}

Approval to conduct the research was granted by the ethics committee from the hospitals. The study was briefly explained to participants who were informed that involvement was completely voluntary and that they could withdraw at any time with no negative implications. Participants signed consent forms.

\section{Results}

The mean age for the study sample was 40.1 years old (standard deviation \pm 12.8 ), ranging from 18 to 70 years old. Job tenure in the nursing profession was, on average, 14.8 years $(\mathrm{SD} \pm 11.2)$ and mean value for paid work time was 46.9 hours/week ( $\mathrm{SD} \pm 19.4)$. About half the sample (49.5\%) worked night shifts; $28 \%$ were registered nurses, $43.4 \%$ were married or lived with a partner.

A total of $29 \%$ of the interviewed were current smokers or had abandoned smoking; $3.4 \%$ reported that had consumed some alcoholic drink in the two weeks that anteceded the interview. Most workers (73.1\%) did not engage in physical activity greater than 1 hour per week, which was consistent with the high prevalence of overweight or obese people $(45 \%)$. A total of $39 \%$ of the workers reported having had their arterial blood pressure measured in the week preceding the interview. The prevalence of self-reported high blood pressure was $32 \%$.

Table 1 describes the results concerning the association between workers' characteristics and self-reported hypertension. Higher prevalence of reporting hypertension were observed for those with the following characteristics: no university degree, mixed and black ethnicity, over weight and obese, after adjustment for age. In addition, self-reported hypertension was more common among those with permanent rather than temporary jobs.

The workers' distribution as to the quadrant formulation was: the high strain group $(n=526)$, the passive job group ( $n=192)$, the active job group $(n=226)$, and the low strain group $(n=307)$. As regards the quotient term, the highest quartile group encompassed 311 workers, while the reference group included 940 workers.

ISSN 2324-7940 E-ISSN 2324-7959 
Table 1: Association between workers' characteristics and self-reported hypertension. Prevalence-ratio (PR) adjusted for age and respective 95\% CI among female nursing workers. Rio de Janeiro/Brazil, 2006, N = 1,307.

\begin{tabular}{|c|c|c|c|c|}
\hline Characteristics & Whole group n (\%) & Non hypertensive group n (\%) & Hypertensive group n (\%) & PR (95\% CI) \\
\hline \multicolumn{5}{|l|}{ Sociodemographic data } \\
\hline \multicolumn{5}{|l|}{ University degree } \\
\hline Yes & $504(38.4)$ & $353(73.1)$ & $130(26.9)$ & 1.0 \\
\hline No & $801(61.3)$ & $499(64.6)$ & $274(35.4)$ & $1.49(1.16-1.91)$ \\
\hline Missing data & $2(0.3)$ & & & \\
\hline \multicolumn{5}{|l|}{ Family income (US \$) } \\
\hline$\geq 423.3$ & $481(36.8)$ & $342(72.6)$ & $129(27.4)$ & 1.0 \\
\hline$<423.3$ & $812(62.1)$ & $503(65.1)$ & $270(37.9)$ & $1.27(0.97-.66)$ \\
\hline Missing data & $14(1.1)$ & & & \\
\hline \multicolumn{5}{|l|}{ Ethnicity/background } \\
\hline White & $479(36.6)$ & $354(76.3)$ & $110(23.7)$ & 1.0 \\
\hline Mixed & $511(39.1)$ & $335(68.8)$ & $152(31.2)$ & $1.46(1.10-1.95)$ \\
\hline Black & $312(23.9)$ & $161(53.3)$ & $141(46.7)$ & $2.81(2.07-3.85)$ \\
\hline Missing data & $5(0.4)$ & & & \\
\hline \multicolumn{5}{|l|}{ Living with partner } \\
\hline No & $737(56.4)$ & $490(69.0)$ & $220(31.0)$ & 1.0 \\
\hline Yes & $566(43.3)$ & $359(66.0)$ & $185(34.0)$ & $1.15(0.90-1.46)$ \\
\hline Missing data & $4(0.3)$ & & & \\
\hline \multicolumn{5}{|c|}{ Health-related behavior variables } \\
\hline \multicolumn{5}{|c|}{ BMI } \\
\hline Underweight/Normal weight & $698(53.4)$ & $549(80.1)$ & $128(18.9)$ & 1.0 \\
\hline Overweight & $373(28.5)$ & $203(57.2)$ & $152(42.8)$ & $2.05(1.49-2.82)$ \\
\hline Obesity & $198(15.2)$ & $74(38.9)$ & $116(61.1)$ & $4.21(2.84-6.23)$ \\
\hline Missing data & $38(2.9)$ & & & \\
\hline \multicolumn{5}{|l|}{ Smoking habits } \\
\hline Never & $927(70.9)$ & $369(71.7)$ & $252(28.3)$ & 1.0 \\
\hline Currently/former smoker & $379(29.0)$ & $213(38.2)$ & $153(41.8)$ & $0.99(0.76-1.29)$ \\
\hline Missing data & $1(0.1)$ & & & \\
\hline \multicolumn{5}{|c|}{ Alcohol intake in the last 14 days } \\
\hline No & $871(66.6)$ & $572(68.3)$ & $265(31,7)$ & 1.0 \\
\hline Yes & $436(33.4)$ & $281(66.7)$ & $140(33.3)$ & $1.20(0.90-1.60)$ \\
\hline \multicolumn{5}{|c|}{ Physical activity in the last 7 days } \\
\hline More than 6 hours & $32(2.4)$ & $23(71.9)$ & $9(28.1)$ & 1.0 \\
\hline 1-6 hours & $319(24.4)$ & $197(63.0)$ & $112(36.2)$ & $1.49(0.47-2.98)$ \\
\hline Not at all or less than $1 \mathrm{hr}$ & $956(73.2)$ & $633(69.0)$ & $284(31.0)$ & $1.40(0.57-3.44)$ \\
\hline \multicolumn{5}{|l|}{ Variables related to work } \\
\hline \multicolumn{5}{|l|}{ Number of jobs } \\
\hline One & $832(63.7)$ & $533(66.4)$ & $270(33.6)$ & 1.0 \\
\hline Two or more & $475(36.3)$ & $320(70.3)$ & $135(29.7)$ & $1.04(0.80-1.35)$ \\
\hline \multicolumn{5}{|c|}{ Type of contractual employment } \\
\hline Permanent jobs & $637(48.7)$ & $299(48.6)$ & $336(51.4)$ & 1.0 \\
\hline Temporary jobs & $666(51.0)$ & $552(86.3)$ & $106(13.8)$ & $1.45(0.97-2.07)$ \\
\hline Missing data & $4(0.3)$ & & & \\
\hline \multicolumn{5}{|l|}{ Work schedule } \\
\hline Day worker & $281(21.5)$ & $203(74.4)$ & $70(25.6)$ & 1.0 \\
\hline Former night worker & $400(30.6)$ & $209(54.1)$ & $177(45.9)$ & $1.32(0.89-1.95)$ \\
\hline Current night worker & $619(47.4)$ & $439(73.9)$ & $155(26.1)$ & $1.09(0.75-1.60)$ \\
\hline Missing data & $7(0.5)$ & & & \\
\hline
\end{tabular}


The association between self-reported hypertension and job strain was statistical significant only when job strain was evaluated using the ratio between demand and control. Workers in the highest quartile of job strain were 1.54 times more likely to report hypertension than the reference group. This association was not statistically significant when the demand control model was assessed by the quadrant term (see Table 2).

Table 2: Prevalence-ratio (PR) and respective $95 \%$ CI for self-reported hypertension and job strain among female nursing personnel. Rio de Janeiro/Brazil, 2006. $(n=1,307)$

\begin{tabular}{|c|c|c|c|c|c|c|}
\hline & \multicolumn{2}{|c|}{ Whole group } & \multirow{2}{*}{ PR crude (95\% CI) } & \multirow{2}{*}{$\begin{array}{l}\text { Multivariate } \\
\text { Model } 1{ }^{*}\end{array}$} & \multirow{2}{*}{$\begin{array}{l}\text { Multivariate } \\
\text { Model } 2^{\#}\end{array}$} & \multirow{2}{*}{$\begin{array}{l}\text { Multivariate } \\
\text { Model } 3{ }^{* *}\end{array}$} \\
\hline & $\mathbf{n}$ & $\%$ & & & & \\
\hline \multicolumn{7}{|c|}{ Demand/control ratio } \\
\hline Low strain & 940 & 71.9 & 1.0 (reference) & 1.0 (reference) & 1.0 (reference) & 1.0 (reference) \\
\hline High strain & 311 & 23.8 & 1.25 (0.99-1.67) & $1.43(1.03-1.98)$ & $1.48(1.05-2.05)$ & $1.54(1.09-2.18)$ \\
\hline Missing data & 56 & 4.3 & & & & \\
\hline \multicolumn{7}{|l|}{ Quadrants } \\
\hline Low strain & 307 & 23.5 & 1.0 (reference) & 1.0 (reference) & 1.0 (reference) & 1.0 (reference) \\
\hline Active job & 526 & 40.2 & $0.86(0.63-1.18)$ & $1.23(0.88-1.73)$ & $1.29(0.92-1.83)$ & $1.30(0.91-1.85)$ \\
\hline Passive job & 226 & 17.3 & $1.15(0.79-1.67)$ & $1.24(0.80-1.85)$ & 1,21 (0.79-1.87) & $1.35(0.84-2.05)$ \\
\hline High strain & 192 & 14.7 & $1.25(0.84-1.83)$ & $1.20(0.78-1.85)$ & $1.16(0.75-1.80)$ & $1.15(0.73-1.80)$ \\
\hline Missing data & 56 & 4.3 & & & & \\
\hline
\end{tabular}

* Multivariate model 1: Adjusted for age

" Multivariate model 2: Model 1+ Adjusted for socio-demographic data: income + self-reported skin color + education + marital status

${ }^{* *}$ Multivariate model 3: Model 2 +Adjusted for health-related factors: BMI, smoking habits

\section{Discussion}

This study indicated that the association between job strain and self reported arterial hypertension in nursing workers depends upon the method used to analyze the demandcontrol model. When evaluating occupational stress based on the quotient between demand and control, individuals exposed to high demand and low control over the job were $54 \%$ more likely to report hypertension. On the other hand, when evaluating occupational stress using the quadrant term (job demands above the sample median and job control below the sample median), individuals exposed to high job strain were only $15 \%$ more likely to report hypertension (in the full model), a result that was not statistically significant.

There is no agreement regarding the best approach to assess job strain based on the demand control model. Among studies that have evaluated the relation between the cardiovascular outcomes and psychosocial work stress are the investigations of Theorell, et al. ${ }^{[14]}$ and Michikawa, et al. ${ }^{[20]}$ that used the quotient term to assess job strain. Both found significant associations between the job strain and heart disease. The quadrant formulation has been used in many studies, for example, by Cesana, et al..$^{[21]}$ and Guimont, et al. ${ }^{[22]}$ who examined casual blood pressure as outcome; and also by Landsbergis, et al. ${ }^{[5]}$ and Clays, et al. ${ }^{[12]}$ who examined ambulatory blood pressure measurements as outcome, both publications showed significant associations as well.

The quotient term constructs a value of occupational stress based on the interaction between levels of job demand and job control. The choice of the cut-off point was the fourth quartile of the distribution, the group most highly exposed to occupational stress. This group was likely to be exposed to situations where the psychological job demands were greater than the level of job control. The more restrictive are the cut-off points the stronger the effects are expected to be produced. In both Riese, et al. ${ }^{[23]}$ and in our study, the relation between occupational stress and blood pressure was assessed in a sample of female registered nurses that on average were close to 40 years old, although Riese, et $a l^{[23]}$ examined this outcome through $24 \mathrm{~h}$ blood pressure monitoring.

Studies on blood pressure employing two or more formulations of the demand-control model are scarce. One of them was published by Landsbergis, et al.,${ }^{[9]}$ who found significant associations between ambulatory systolic blood pressure and all formulations of job strain (quadrants, tertiles, and subtraction) for male employees. The non association here described for the quadrant-based job strain and reported hypertension confirm results from other authors, who also tested job strain using quadrants and its association with casual ${ }^{[16]}$ or ambulatory blood pressure measure among women. ${ }^{[23]}$ In the latter study, with nursing workers, the authors suggested psychological and physiological mechanisms for explaining putative gender differences in detrimental consequences of job strain. According to results here described, the quadrant formulation was not as sensible as regards self-reported hypertension as the quotient term, which may have contributed to the negative results described above. 
The higher frequency of self-reported arterial hypertension among older, black and/or mixed race and obese women are consistent with the literature. Particularly relevant are the results of a population study by Borrell, et al. ${ }^{[24]}$ that found that African Americans were more likely to self-report arterial hypertension. Similarly, in the present analysis, black women were shown to have a higher risk of hypertension. We also found that nursing personnel with no university degree report more hypertension than those with a University degree. In Brazil, obtaining a university diploma is indicative of a privileged social position; thus, this finding reflects the association between lower socio-economic status and hypertension. Low socio-economic level is associated with a variety of biological (metabolic syndrome, obesity) and behavioral (smoking habits, sedentarism) risk factors $^{[25]}$ and, consequently, with hypertension and cardiovascular diseases. ${ }^{[5]}$

Among the limitations of the present study is the use of self-report to determine the health outcome measure. Hernberg $^{[26]}$ comments on reports on depression, hypertension and insomnia which are filled with emotional conflicts, which may lead answers to be influenced by the effects of occupational stress. Although self-report hypertension may be subject to error, there is no reason to think that this has influenced results here described. Despite this, evidences of the validity of self-reported hypertension were described by Vargas, et al. ${ }^{[14]}$ In addition, the cross-sectional design of our study does not allow us to determine a causal relationship between job strain and hypertension. It is possible that workers who report hypertension may be more sensible to work demands than the others, a limitation that demands a longitudinal approach to be dealt with. Another potential limitation is related to the variance in the working condition of the sample. Duties of nurses and nurses' assistants were somehow different, and this was not considered here. It is noteworthy that low scale reliability for the job control component of job strain may have led the observed results to be weaker than otherwise. This result are discussed by Griep, et al. ${ }^{[19]}$ in relation to scale psychometric properties for the same workers sample.

One of the strengths of the present study is the test-retest reliability of the self-report measure of hypertension. In addition, the sample was formed by nursing professionals involved with patient care, with easy access to the necessary instruments to measure their own arterial blood pressure or health services which would conduct such measurement. Thirty-nine per cent of the workers reported having had their arterial blood pressure measured within seven days of the interview. Moreover, the utilization of self reported morbidity data in epidemiologic investigations is justifiable for its practicality and low cost. Particularly important is the fact that studies about hypertension prevalence involve costly methods as it is the case of the ambulatory monitoring of the blood pressure. In this case the individual report concerning its own health state can represent a more feasible alternative for the arterial blood pressure monitors.

In conclusion, the present study contributes to this debate by focusing on self-reported hypertension among female workers, reinforcing that job strain formulation should be taken into account in studies on psychosocial work environment. Self-reported hypertension should be considered as an alternative way to assess this outcome in epidemiologic investigations. The present results encourage further analyzes on psychosocial work environment and its implications on the health of nursing professionals.

\section{Acknowledgements}

RHG and LR are recipients of research productivity grants from CNPq (Brazilian Council for Scientific and Technological Development). RHG and LR are fellows of the Irving Selikoff International Fellows of the Mount Sinai School of Medicine ITREOH Program. Their work was supported in part by grant 1 D43 TW00640 from the Fogarty International Center of the National Institutes of Health. Additional financial support: Brazilian National Research Council (CNPq) and Carlos Chagas Filho Foundation for Research Support in the State of Rio de Janeiro (FAPERJ).

\section{References}

[1] Belkic KL, Landsbergis P, Schnall PL, Baker D. Is job strain a major source of cardiovascular disease risk? Scand J Work Environ Health. 2004; 30(2): 85-128. http://dx . doi.org/10.5271/s jw eh. 769

[2] Waldron I, et al. Cross-cultural variation in blood pressure: a quantitative analysis of the relationships of blood pressure to cultural characteristics, salt consumption and body weight. Social Science and Medicine. 1982; 16(4): 419-30. http://dx.doi.org/10.10 16/0277-9536 (82) 90050-8

[3] Hajjar I, Kotchen J, Kotchen T. Hypertension: Trends in Prevalence, Incidence, and Control. Annual Review of Public Health. 2006; 27: 465-490. http://dx.doi.org/10.1146/annurev.p ublhealth.27.021405.102132

[4] Landsbergis PA, et al. The workplace and cardiovascular disease. In Quick J, Tetrick L (eds.) Handbook of Occupational Health Psychology. Second Edition.Washington, DC: American Psychological Association; 2011. 441 p.

[5] Landsbergis PA, Schnall PL, Pickering TG, Warren K, Schwartz JE. Life-course exposure to job strain and ambulatory blood pressure in men. American Journal of Epidemiology. 2003; 157: 998-1006. http://dx.doi.org/10.1093/aje/kwg095

[6] Karasek R.A. Job demands, job decision latitude and mental strain: Implications for job redesign. Adm. Sci. Q. 1979; 24: 285-308. http://dx.doi.org/10.2307/2392498

[7] Landsbergis P, Dobson M, Koutsouras G, Schnall P. Job Strain and Ambulatory Blood Pressure: A Meta-Analysis and Systematic Re- 
view. Am J Public Health. 2013; 103: e61-e71. http: //dx .doi . o rg/10.2105/AJPH. 2012.301153

[8] Babu GR, et al. Is hypertension associated with job strain? A metaanalysis of observational studies. Occup Environ Med. 2014; 71: 220-227. http://dx.doi.org/10.1136/oemed-2013-101396

[9] Karasek R, Theorell T. Healthy Work: Stress, Productivity and the Reconstruction of Working Life. New Yourk: Basic Books, Inc. Publishers; 1990. 381 p.

[10] Landsbergis PA, Schnall PL, Schwartz JE, Pickering TG, Warren $\mathrm{K}$. The association of ambulatory blood pressure with alternative forms of job strain. Scand J Work Env Health. 1994; 20: 349-63. http://dx.doi.org/10.5271/sjweh.1386

[11] Goldstein IB, Shapiro D, Chicz-DeMet A, Guthrie D. Ambulatory blood pressure, heart rate, and neuroendocrine responses in women nurses during work and off work days. Psychosom. Med. 1999; 61: 387-396. PMid:10367621. http://dx.doi.org/10.1097/0 0006842-199905000-00020

[12] Clays E., et al. High job strain and ambulatory blood pressure in middle-aged men and women from the Belgian job stress study. J. Occup. Environ. Med. 2007; 49: 360-367. PMid:17426519. http: //dx.doi.org/10.1097/JOM.0b013e31803b94e2

[13] Tsutsumi A, Kayaba K, Tsutsumi K, Igarashi M, Group JMSCS. Association between job strain and prevalence of hypertension: a cross sectional analysis in a Japanese working population with a wide range of occupations: the Jichi Medical School cohort study. Occup Environ Med. 2001; 58(6): 367-373. http://dx.doi.org /10.1136/oem.58.6.367

[14] Theorell T, et al. Decision latitude, job strain, and myocardial infarction: A study of working men in Stockholm. The SHEEP Study Group. Stockholm Heart epidemiology Program. Am. J. Public Health. 1998; 88: 382-388. PMid:9518968. http://dx.doi.o rg/10.2105/AJPH.88.3.382

[15] Vargas CM, Burt VL, Gillum RF, Pamuk ER. Validity of self-reported hypertension in the National Health and Nutrition Survey III, 1988-1991. Preventive Medicine. 1997; 26: 678685. PMid:9327477. http://dx.doi.org/10.1006/pmed. 1997 .0190

[16] Pickering TG, Devereux RB, James GD, Gerin W, Landsbergis P, Schnall PL, et al. Environmental influences on blood pressure and the role of job strain. J Hypertens Suppl. 1996 Dec; 14(5): S179-85. PMid:9120676.

[17] Rotenberg L, Portela LF, Banks B, Griep RH, Fischer FM, Landsbergis P. A gender approach to work ability and its relationship to professional and domestic work hours among nursing personnel. Appl Ergonomics. 2008; 39(5): 646-652. http://dx. doi.org/d oi/10.1016/j.apergo.2008.02.013

[18] Alves MGM, Chor D, Faerstein E, Lopes CS, Werneck GL. Job strain and hypertension in women: Estudo Pró-Saúde (Pro-Health Study). Revista de Saúde Pública. 2004; 38: 164-171. http://dx .doi .org/10.1590/S0034-89102009000500019

[19] Griep RH, Rotenberg L, Vasconcellos AG, Landsbergis P, Comaru $\mathrm{CM}$, Alves MG. The psychometric properties of demand-control and effort-reward imbalance scales among Brazilian nurses. Int Arch Occup Environ Health. 2009; 82(10): 1163-72. PMid:19756699. http://dx.doi.org/10.1007/s00420-009-0460-3

[20] Michikawa T, Nishiwaki Y, Nomiyama T, et al. Job strain and arteriosclerosis in three different types of arteries among male Japanese factory workers. Scand J Work Environ Health. 2008; 34(1): 48-54. PMid:18427698. http://dx.doi.org/10.5271/sjweh.1163

[21] Cesana G, Ferrario M, Sega R, Milesi C, Vito GD, Mancia G, et al. Job strain and blood pressure in employed men and women: a pooled analysis of four Northern Italian population samples. Psychosom Med. 2003; 65(4): 558-563. http://dx.doi.org/10.10 97/01.PSY.0000041473.03828.67

[22] Guimont C, Brisson C, Dagenais GR, Milot A, Vézina M, Mâsse B, et al. Effects of job strain on blood pressure: A prospective study on male and female white-collar workers. Am. J. Public Health. 2006; 96: 1436-1443. PMid:16809603. http://dx.doi.org/10.2105 /AJPH. 2004. 057679

[23] Riese H, Van Doornen LJ, Houtman IL, De Geus EJ. Job strain in relation to ambulatory blood pressure, heart rate, and heart rate variability among female nurses. Scand J Work Environ Health. 2004; (30)6: 477-85. http://dx.doi.org/10.5271/sjweh. 837

[24] Borrell LN, Crawford N, Huynh M, Dumanovsky T. Self-reported hypertension and race among hispanic and non-hispanic adults: the new york city community health survey. Ethnicity \& Disease. 2008; 18: 299-305. PMid:18785443.

[25] Steptoe A, Kunz-Ebrecht S, Owen N, Feldman PJ, Willemsen G, Kirschbaum C, et al. Socioeconomic Status and Stress-Related Biological Responses Over theWorking Day. Psychosomatic Medicine. 2003; 65: 461-470. PMid:12764220. http://dx.doi.org/10.10 97/01.PSY.0000035717.78650.A1

[26] Hernberg S. Work-related diseases: some problems in study design. Scand J Work Environ Health. 1984; 10: 367-72 PMid:6336012. http://dx.doi.org/10.5271/sjweh. 2317 